\title{
La herejía de cada uno y el amor como escritura, frente a la pandemia del Uno solo
}

\author{
The end of the f...ing world | Jonathan Entwistle | 2017 \\ Claudia Lijtinstens
}

Asociación Mundial de Psicoanálisis | Fundación AVENIR, Argentina

Recibido: 2 de agosto 2020; aceptado: 14 de agosto 2020

\begin{abstract}
Resumen
Frente a la soledad contemporánea, agravada por los pandémicos acontecimientos de lo real, se exponen algunas salidas posibles por la vía de la herejía como posición del ser, pero también por la vía del amor como soporte de un encuentro, en el sentido de un lazo que habilite salir del autoerotismo y atemperar aquello imposible de soportar, a partir de la serie de televisión inglesa The end of The f... World (Entwistle, 2017). Un lazo amoroso y novedoso donde cada uno de los personajes, auténticos desabonados al inconsciente, en su despertar adolescente, buscan una suplencia en ese compañero sinthomático. Será el psicoanálisis, desde cierta insociabilidad e insumisión herética, el que podrá hacer lugar a una respuesta del sujeto enlazando ese objeto que hace de él algo singular en una travesía que nombra el anudamiento entre sinthoma e identidad.
\end{abstract}

Palabras clave: Psicoanálisis | soledad | sinthoma | identidad | series

The heresy of each and love as writing, in the face of the pandemic of the One alone

Abstract

Faced with contemporary loneliness, aggravated by the pandemic events of reality, some possible solutions are exposed by way of heresy as a position of being, but also by way of love as a support for an encounter, in the sense of a bond that enables getting out of autoeroticism and tempering what is impossible to bear, based on the English television series The end of The $\mathrm{f}$... World (Entwistle, 2017). A loving and new bond where each of the characters, authentic unsubscribed to the unconscious, in their adolescent awakening, look for a substitute in that symptomatic partner. It will be psychoanalysis, from a certain unsociability and heretical insubordination, which will be able to make room for a response from the subject by linking that object that makes it something unique in a journey that names the knot between sinthoma and identity.

Keywords: Psychoanalysis | loneliness | sinthome | identity | series

La insensatez de los acontecimientos de lo real y de la virulencia de lo que circula en el demos, que desconfigura tiempos y espacios, se instaura una especie de urgencia colectiva que profundiza la tiranía del Uno solo, del “individualismo de masa”, como lo dice Laurent (2014, p.1), donde el autoerotismo y la satisfacción solitaria crean la ilusión de poder prescindir del amor, del encuentro y hasta de la división del lenguaje mismo.

Algo de una soledad radical, aunque se esté embrollado en historias y cuerpos, deja a cada Uno solo con su goce (Miller, 2020, p.7).

Hay algo de esta soledad desnuda en estos jóvenes a los que me voy a referir, tomados en sus propios circuitos autoeróticos, enajenados, desconectados, melancolizados, absortos o silenciados en sus narcisismos, sin escuchar ni ser escuchados en el acontecer de la vida.
Se trata de adolescentes que hacen del rechazo y de la nulificación de la expresividad (Byung, 2016) un modo de estar en el mundo (hasta prescinden, hoy, del uso de las tecnologías), como uno del nombres de ese rechazo al estándar normativizado por el Otro, como un modo de rebelarse frente a lo imposible de soportar, transitando entre la ira (cuando las clavijas no entran en los agujeritos) y la angustia, como índice de lo real, que solo se ve atenuado o moderado por una empatía que el amor, como soporte de ese encuentro, produce (Lacan, 1958).

Podemos pensar la herejía como una posición del ser que cuestiona, de una manera controversial, creencias, conceptos o los discursos establecidos.

Cuando Lacan (1975) en el Seminario XXIII juega con la homofonía y escribe el sinthome madaquin / ortodoxo y el sinthome rule/ herético ${ }^{1}$ (Miller, 2006), lo hace para

clijtinstens@gmail.com 
pensar ya no las identidades como un proceso de identificación sino como síntoma, como aquello desigual, la identidad sinthoma (Miller, 2013, p.140). Un significante impar que posibilita nombrar una existencia en un ser o un hacer.

La ortodoxia sería entonces un régimen particular del sinthome por la vía del padre, una identificación que se sirve del proceso identificatorio edípico que concilia con los semblantes sociales a partir del velo de las sublimaciones.

Lo herético, en cambio, revela el desnudado -en su estructura y en su real- de los semblantes, aquello que desmarca de la norma.

Una preciosa serie televisiva inglesa titulada "The end of the f...ing world" ' (Jonathan Entwistle, 2017), nos permite apreciar algo de ese desmarcado de la norma a través de la historia de dos adolescentes profundamente desarraigados del Otro, solitarios, a la deriva del Uno solo de la época, a quienes su desapego de los discursos establecidos y su profunda insociabilidad los lleva a un derrotero en el que el amor -en tanto lazo que media entre el sujeto y aquello que hace de él algo único- cobra un sostenido protagonismo (Arenas, 2012).

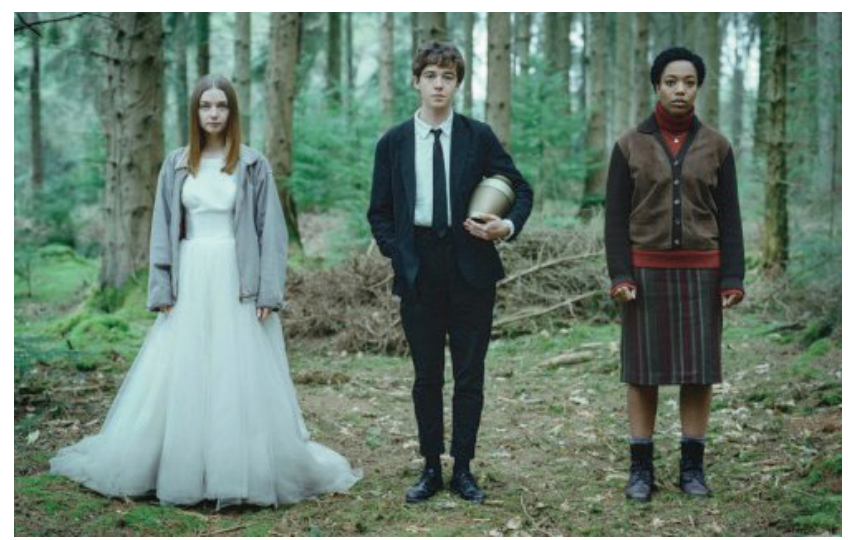

cY creo que esa insociabilidad, ese estar un poco por fuera de las convenciones sociales y de los valores comunes, enmarcados en la ética del bien, hace de este relato algo que puede interesar a quienes están implicados en causar y encarnar el discurso analítico, ese que Lacan define como un nuevo lazo social.

Y es que el psicoanalista está intrínsecamente ligado a cierta insociabilidad frente a los ideales comunes, a una particular insumisión a ser clasificado en los lazos sociales, aún frente al discurso analítico mismo o la ortodoxia freudiana, como dice Miller (2018).

Podemos ubicar en el relato cinematográfico dos ejes que se van entrelazando a lo largo de los capítulos.

Por un lado, escenas y trayectos narrativos en los que se pueden precisar modalidades de salidas de la pubertad y las soluciones que aparecen en la adolescencia, adolescencia que pensamos como síntoma de la pubertad por un lado, pero también como el fracaso de la metáfora puberal frente a la inflación imaginaria, generando una salida por el lado de lo imaginario y la pulsión, en una metonimia hacia la consumición en la que se ven arrastrados los jóvenes (Lijtinstens, 2010).

Por otro, podemos interrogar la vía del amor, del partenaire amoroso, en el sentido de un lazo que habilita salir del autoerotismo y atemperar aquello imposible de soportar. El amor como eso contingente que "cesa de no escribirse" (Lacan, 1972, p.175) y que habilita inscribir algo de lo imposible de la relación.

Lacan, en el prefacio de "El Despertar de la primavera" de 1974, expone algunas consideraciones sobre la adolescencia pero no desde la perspectiva de un tiempo cronológico vinculado al desarrollo madurativo sino como un reencuentro con algo ya establecido por el sujeto respecto a su modo de satisfacción, como un momento de reelección, un tiempo en el que una decisión subjetiva se precipita ante el vacío de saber sobre el sexo.

$\mathrm{Y}$ en el lugar de ese imposible de saber cada uno inventa una respuesta sintomática para arreglárselas con el ser y con el sexo, con la elección de objeto, con las identificaciones, con los ideales que hasta ese momento imperaban.

Cada adolescente da testimonio, a su manera y con un profundo desgarro, de cómo la sexualidad hace agujero en lo real, confrontándose con una grieta en el saber que a la vez cuestiona el saber del Otro. "Agujero en el saber y agujero en la intimidad de la sexualidad del niño”, dice Lacadee (2017, p.63).

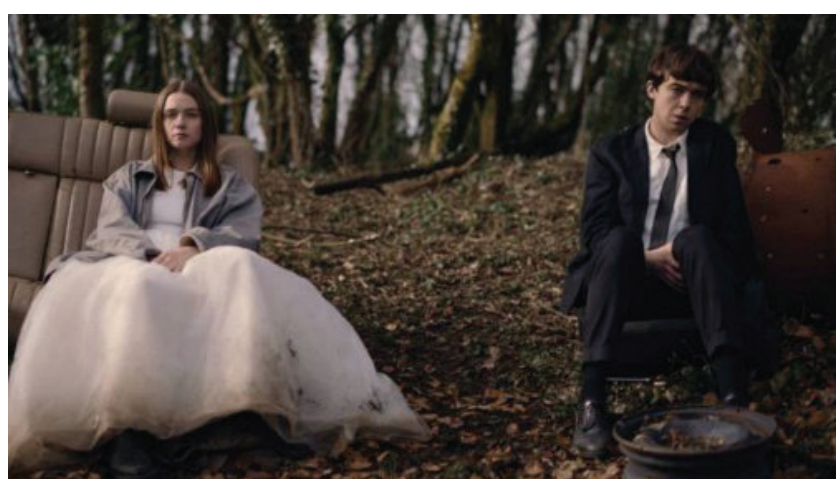

Se trata también, la adolescencia, de una crisis de la lengua articulada. El adolescente prefiere procurarse un S1 (solo) que anude cuerpo y pensamiento, apelando a esa peculiar ironía cuestionadora del saber del Otro.

En este relato, esto es llevado a su extremo más sustancial, mostrando cómo el significante se desarticula estructuralmente, se desencadena, perturbando el lazo 
al Otro, quedando articulado sólo a la pulsión, produciendo una desquicia lenguajera, una errancia verbal y hasta física que conduce a los personajes a situaciones y experiencias de gran crudeza, pero también de singular belleza ficcional. El maldecir presente en el título del relato muestra con elocuencia la injuria inherente a ese imposible de enunciar que embrolla al parlêtre cuando está un poco fuera del Otro.

En estos personajes, el incumplimiento simbólico de la metáfora desencadena una inflación imaginaria, una salida por el lado de lo imaginario y de la pulsión, provocando una "metonimia infernal" en la égida del rechazo y la exclusión (Miller, 2015, p. 10). En este caso, el uso de la "ironía infernal del esquizofrénico" (p.1), como lo dice Miller (1988), está muy elocuentemente descripta como esa "arma ante la raíz misma de toda relación social” (Lacan, 1966, p. 227).

$\mathrm{Y}$ es que, cuando ese nudo de tres (RSI) no se constituye, la metamorfosis del cuerpo y la imagen de sí que se anuda a un real de la vida, no se condensa. $Y$ esto conduce al sujeto a un exilio, a una huida, a una expulsión, que lo fuerza a experimentar el vacío hasta el arrebato, producto del fracaso de poder nombrar lo real de la sexualidad.

En la psicosis, hay el agujero en la cadena significante, agujero que no es simbolizable. $\mathrm{Y}$ a ese lugar viene a responder la pulsión. Pero no la pulsión civilizada, domesticada, sino la pulsión en lo real del cuerpo en su forma irreprimible, furiosa, peligrosa, que se traduce casi sin escapatoria en el pasaje al acto, la alucinación o el delirio.

Auténticos desabonados al inconsciente, con sus narcisismos exaltados, sostienen con una innegable certeza la ausencia de su división subjetiva.

Él, silencioso, abstraído en sus pensamientos "criminales" casi del orden de la imposición, detenido ante su traumatismo, se "corporiza" y encuentra en ella la vitalidad necesaria para inscribirse en ese "plan" que ella tácitamente comanda.

Ella, en perpetuo y destructivo deslizamiento metonímico, siempre con un Otro abusivo como partenaire, escupe palabras como balas que atraviesan cada escena, rechaza todo semblante y encuentra, en la relativa sensatez que él sostiene, la protección necesaria frente a las calamidades que se le presentan, pasando de la idealización del padre a su destitución absoluta, de la melancolía desoladora a la exaltación, sin puntos medios, aún hasta la propia caída melancólica.

Y el resto de los personajes de la historia muestran, también, un fuera de norma muy particular: en lo abu- sivo del profesor que maltrata, de los progenitores que descuidan, pero también lo inclasificable de otros atravesados por lo más hétero, lo más femenino, revelando el envés de la norma, de la regla, plasmando ingeniosamente cada uno de ellos ese elemento herético.

Pero el amor produce un lazo novedoso donde cada uno de estos personajes busca un soporte, una suplencia en ese compañero sinthomático. En esa infernal huida en la que los acontecimientos se entrelazan en un patético, bizarro, pero profundamente romántico relato, los personajes nos revelan el trabajo que hacen, cada uno, para encontrar algo de una representación propia de un ser, de una existencia, por fuera del Otro y de la norma. Pero cada uno de los personajes toma un valor esencial para el otro y tiene la función de salvar su dignidad de sujeto.

Lacan (1960) nos dice en el Seminario VIII que el amor está relacionado con la pregunta planteada al otro acerca de lo que puede darnos y lo que tiene que respondernos. Y que en ese lazo entre el sujeto y aquello que hace de él algo singular radica nada menos que su propia dignidad; es lo que le permite salir del autoerotismo para dar lugar, como dice Miller, a un "auto-hétero-erotismo" (2012, p.47).

Para terminar, diría que el despertar de la adolescencia sin los sueños, sin las ficciones, sin las ensoñaciones, como estos personajes nos revelan tan radicalmente, solo deja lugar a la angustia y al desarraigo subjetivo, al acting o al pasaje al acto.

Son los sueños los que permiten ir tramando variaciones como medio de poner en movimiento el deseo y la satisfacción, como mojones que indican referencias al propio cuerpo, al otro, a lo enigmático del encuentro con el Otro sexo.

Quizás se trate, como lo evoca Lacan de "ser hereje de la buena manera". De una manera en la que, "habiendo reconocido la naturaleza del sinthome, no se priva de usarlo lógicamente, es decir, de usarlo hasta alcanzar su Real, al cabo de lo cual él apaga su sed" (Lacan, 1975, p.15).

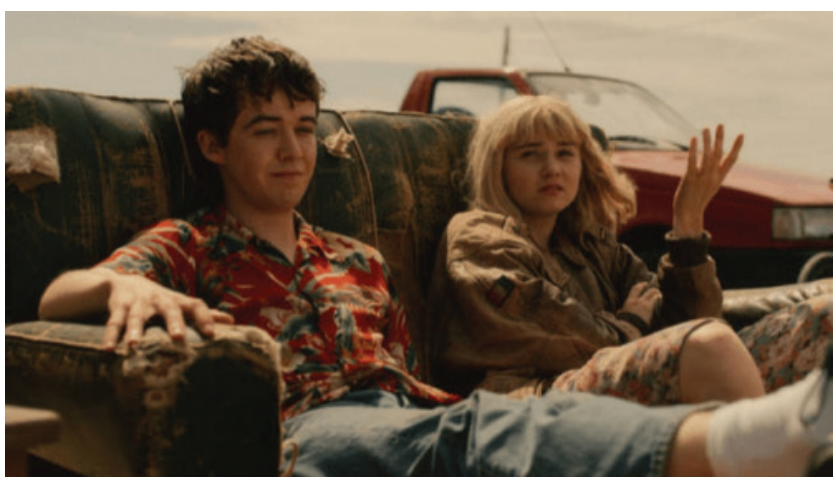




\section{Referencias}

Arenas, G. (2012). La flecha de Eros. Buenos Aires: Grama Ediciones.

Han, B-C. (2016). La agonía del Eros. Buenos Aires: Herder Editorial.

Lacadee, P. (2017).Los sufrimientos modernos del adolescente. Buenos Aires: UNSAM Edita.

Lacan, J. (1972). Aun. El Seminario de Jacques Lacan. Libro 20. Buenos Aires: Paidós.

Lacan, J. (1958). El deseo y su interpretación. El Seminario de Jacques Lacan. Libro VI. Buenos Aires: Paidós

Lacan, J. (1974). Prefacio a El despertar de la primavera. En Otros escritos. Buenos Aires: Paidós.

Lacan, J. (1960). La transferencia. El Seminario de Jacques Lacan. Libro VIII. Buenos Aires: Paidós.

Lacan, J. (1966). Respuestas a Estudiantes de Filosofía. En Otros escritos. Buenos Aires: Paidós.

Laurent, E. (2014). La época en que la política daba respuestas a la pregunta por el sentido está terminada. Télam. Recuperado de: https://www.telam.com.ar/notas/201403/56862-la-epoca-en-que-la-politica-daba-respuestas-a-la-pregunta-por-el-sentido-esta-terminada.html

Lijtinstens, C. (2010). Billy Elliot y el hallazgo de un deseo. En Enlaces XVI. Buenos Aires: Grama Ediciones.

Macdonald, E., Ferguson, M., Baker, A., Fried, P., Buchanan, D. y Entwistle, J. (productores) y Entwistle, J. (creador). (20172019). The End of the F...ing World [serie televisiva]. Reino Unido: Clerkenwell Films-Dominic Buchanan Productions.

Miller, J-A .(2020). La soledad del goce. Registros. Buenos Aires: Ricardi.

Miller, J-A. (2018). Del sintoma al fantasma. Y retorno. Los cursos psicoanalíticos de Jacques-Alain Miller. Buenos Aires: Paidós.

Miller, J-A (2015). Prólogo. En Amadeo de Freda, D. (2015). El adolescente actual. Buenos Aires: UNSAM Edita.

Miller, J-A. (2013). El últimisimo Lacan. Los cursos psicoanalíticos de Jacques-Alain Miller. Buenos Aires: Paidós.

Miller, J-A. (2012). El sintoma charlatan. Buenos Aires: Paidós.

Miller, J-A. (1988). Conferencia de apertura del V Encuentro Internacional del Campo Freudiano. Recuperado de: http://psicoanalisisbaires.blogspot.com/2019/02/ironia-j-miller-conferencia-de-apertura.html

1 Sinthoma madaquin, homófono en francés de Saint Thomas d'Aquin, Santo Tomas de Aquino, suena a hombre santo. En inglés, sin es pecado, home hogar y rule regla, homerule, autogobierno, la regla del hogar

2 Basada en el comic del estadounidense Charles S. Forsman, The end of the fucking world. 